\title{
INVESTIGATION ON MICRO STRUCTURAL, MECHANICAL AND TRIBOLOGICAL PROPERTIES OF ALUMINIUM NITRIDE (ALN) COATING DEPOSITED BY RF MAGNETRON SPUTTERING
}

\author{
R.Hariharan ${ }^{1}$ and R.Raja ${ }^{2}$
}

\begin{abstract}
Aluminium nitride thin film deposited by 1018 low carbon steel substrate using RF magnetron sputtering in discharge a mixture of $\mathrm{Ar}$ and $\mathrm{N} 2$ gas .Crystal structure, microstructure and topography was analyzed by X-Ray diffractometry (XRD), Atomic force microscopy(AFM), Raman effect respectively. The influence of deposition time on the surface roughness, hardness, corrosion behaviour ,specific wear for the obtained. film evaluate by mean of tribological was tested. These kind of investigation to use wonderful wear resistance, lower co-efficient of friction \&amp; protection coating is simply too nice plagued by the open porousness of the films. . Stress measurements showed that the role of temperature among the development of the coatings adhesion cannot be explained by a decrease of the strain among the films chemistry tests pointed to the particular proven fact that the protection of the 1018 steel substrates by AIN coatings is attributable to its insulating nature. However, this protection is, to a superb extent littered with the open porosity of the films that's still quite high.
\end{abstract}

Keywords : AIN; RF Sputtering; Coatings; Corrosion; Porosity; Stress measurement;Tribology

\section{INTRODUCTION}

Aluminium is a soft metal that is brittle but strong. Nitrides are a class of chemical compounds in which nitrogen is combined with an element of similar or lower electro negativity. The morphology of aluminium nitride nanoparticles is spherical and their appearances an off-white powder. Aluminium nitride nanoparticles are known for their small particles size distribution, high heat resistance, high surface activity, high level of purity, firmness, large specific surface area, low bulk density and good performance of injection molding[1-3].These can be readily used with composite materials, and are good match with the semiconductors silicon. Aluminium compound nanoparticles area unit hierarchical as irritants which will cause severe skin burns and eye injury. If inhaled, there area unit probability of allergic reaction, respiratory disease symptoms or respiratory difficulties occurring. The dispersion performance of metal compound naoparticles are going to be laid low with damp reunion, thence they have to be sealed in vaccum and hold on in cool and dry surroundings. number thirteen compound (AlN) layers unit of measurement among the foremost partaking materials investigated over the past a few years thanks to their peculiar choices, like high resistivity (1011-1013 ohm.cm), high thermal natural phenomenon, high hardness (11-15 $\mathrm{GPa}$ ), wide band gap vi.0-6.2 eV, high speed of acoustic waves. These exceptional properties produce AlN a extremely promising candidate for a spread of technological applications: surface passivation of thin films, barrier layers in physics, various surface wave (SAW) devices, protection of optical elements.

\section{EXPERIMENTAL DETAILS}

\subsection{Materials}

The alloy studied here was AISI 1018 with the following chemical composition (wt. \%): C, 0.20; Mn, 0.90; Fe; 99.26, balance. The sample consisted disks of $25 \mathrm{~mm}$ in diameter and $3 \mathrm{~mm}$ in thickness. The samples surfaces were fine-ground

\footnotetext{
${ }^{1}$ Department of mechanical engineering, Bharath university, Chennai 73, India.

${ }^{2}$ Department of mechanical engineering, Bharath university, Chennai 73, India.
} 
victimization 200, 400, 600, 800, 1000, and 1200 grit assail paper and eventually it were polished with diamond paste. The substrates were cleaned in academic degree supersonic tub cleaner victimization solvent.

\subsection{Sputtering Method}

Sputtering technique was administrated in 285 metric linear unit diameter and 2 hundred metric linear unit height stainless-steel vacuum Balzers victimization R.F. Thermionic tube sputtering. The samples were placed on the sample holder having as academic degree anode with the connectedness the chamber wall. The chamber was exhausted to base pressure of seven. 6 × 10-2 mm Hg and high purity inert gas was introduced at pressure $7.6 \times 10-2 \mathrm{~mm} \mathrm{Hg}$. Next, the target was sputtered-cleaned at $300 \mathrm{~V}$, sputter current eighty $\mathrm{mA}$ for $10 \mathrm{~min}$ then gas $(99.96 \%$ pure) was introduced and so the operative gas mixture was adjusted to total pressure zero. 6 x 10-2 mm Hg. The substrates weren't heated externally. The substrates temperature were mounted at whole completely different temperature like $\mathrm{RT}, 200^{\circ} \mathrm{C}, 400^{\circ} \mathrm{C}, 500^{\circ} \mathrm{C}, 600^{\circ} \mathrm{C}$, assumed to result from plasma heating attributable to particle bombardment. Purities of Al target was ninety nine.999\% with twenty five metric linear units in diameter and three metric linear unit in thickness, having as a cathode. A schematic diagram of the R.F. thermionic tube sputtering system used in our experiments is shown in Fig. 1.

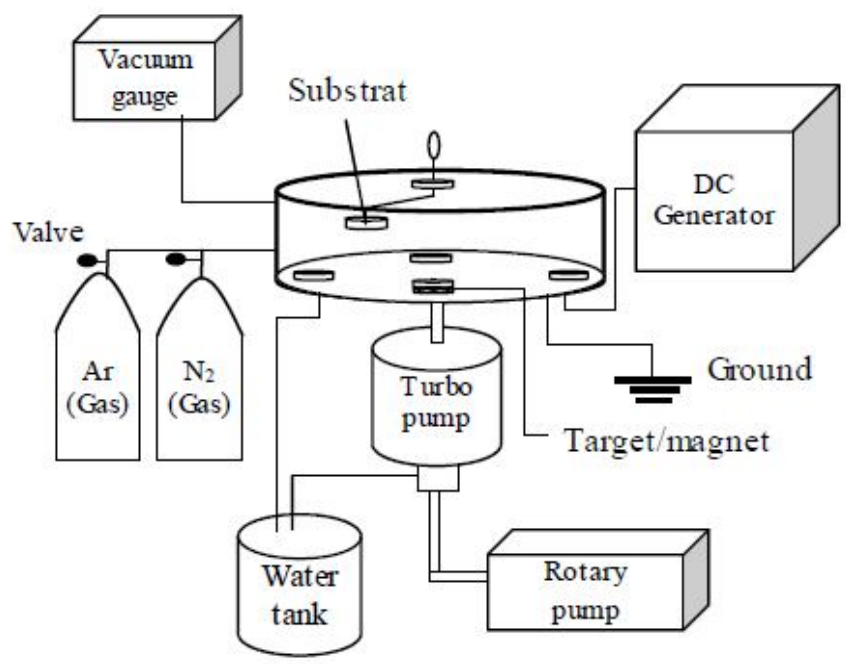

Fig.1. Schematic diagram of the R.F. vacuum tube sputtering

\subsection{Atomic Force Microscopy (AFM)}

The atomic force microscopy (AFM) is one moderately scanning probe microscopes (SPM). SPMs unit of measurement designed to live native properties, like height, friction, magnetism, with an enquiry. To accumulate an image, the SPM raster-scans the probe over slightly house of the sample, measuring the native property at identical time. AFMs operate by measuring force between an enquiry and so the sample. Normally, the probe could also be a pointy tip which will be a 3-6 um tall pyramid with $15-40 \mathrm{~nm}$ end radius. Though the lateral resolution of AFM is low $(\sim 30 \mathrm{~nm})$ as a results of the convolution, the vertical resolution is up to zero. $1 \mathrm{~nm}$. To accumulate the image resolution, AFMs can sometimes live the vertical and lateral deflections of the cantilever by exploitation the optical lever. The optical lever operates by reflective a beam of sunshine off the cantilever. The reflected beam of sunshine strikes a position-sensitive photo-detector consisting of four-segment photo-detector. The variations between the segments of photo-detector of signals indicate the position of the laser spot on the detector and so the angular deflections of the cantilever.Piezo-ceramics build it accomplishable to form three-dimensional positioning devices of haphazardly high exactness. Up-to-date mode, AFMs uses feedback to manage the force on the sample. The AFM not entirely measures the force on the sample but in addition regulates it, allowing acquisition of images at very low forces. The feedback loop consists of the tube scanner that controls the height of the tip; the cantilever and optical lever, that measures the native height of the sample; and a electrical device that tries to remain the cantilever deflection constant by adjusting the voltage applied to the scanner. A well-constructed electrical device is crucial to scientific instrument performance. 
The analyzed material is finely ground, homogenized, and average bulk composition is set. grievous bodily damage von Laue, in 1912, discovered that crystalline substances act as three-dimensional physical phenomenon gratings for X-ray wavelengths similar to the spacing of planes in Associate in Nursing passing lattice. optical phenomenon is presently a typical technique for the study of crystal structures and atomic spacing. optical phenomenon is based on constructive interference of monochromatic X-rays and a crystalline sample. The interaction of the incident rays with the sample produces constructive interference (and a diffracted ray) once conditions satisfy Bragg's Law $(n \lambda=2 d \operatorname{dsin} \theta)$. This law relates the wavelength of radiation to the physical phenomenon Associate in Nursinggle and so the lattice spacing in an passing crystalline sample. These diffracted Xrays unit then detected, processed and counted. By scanning the sample through a ramification of 20 angles, all potential physical phenomenon directions of the lattice got to be attained thanks to the random orientation of the powdered material. Conversion of the physical phenomenon peaks to d-spacing's permits identification of the mineral as results of each mineral includes a group of distinctive d-spacing. Typically, typically this can be often achieved by comparison of d-spacings with traditional reference patterns.

\subsection{Nanoindentation}

Nano indentation may well be a kind of indentation hardness tests applied to tiny volumes. Indentation is maybe the foremost normally applied suggests that of testing the mechanical properties of materials in Associate in Nursing exceedingly\} terribly ancient indentation take a look at (macro or very little indentation), significant a tough \} tip whose mechanical properties unit of measurement proverbial (frequently fictional from a awfully arduous material like diamond) is ironed into a sample whose properties unit of measurement unknown. The load placed on the indenter tip is enhanced as a result of the tip penetrates any into the specimen and shortly reaches a user-defined worth. At now, the load might even be command constant for a amount or removed. The realm of the residual indentation among the sample is measured and to boot the hardness, , is formed public as a results of the foremost load, , divided by the residual indentation space, :

$$
H=\frac{P_{\max }}{A_{\mathrm{r}}}
$$

Nan indentation could be a sturdy technique for determination of skinny film properties that standard testing isn't possible

\subsection{Salt Spray Test}

This accelerated laboratory check was fictional at the starting of the twentieth century. It gives a controlled corrosive atmosphere associate degreed has been wont to provide relative corrosion-resistance information for specimens of metals and coated metals exposed in an extremely check chamber. The classical salt spray (fog) check ASTM B117 consists of atomizing a salt resolution into uniform droplets on specimens supported or suspended between $15-30^{\circ}$ from the vertical. The salt resolution is a solution of fifty (in weight) of $\mathrm{NaCl}$, (more than ocean water that's barely $1.8 \%$ to GHB $3 \%$ ). The exposure zone of the salt spray chamber is maintained at $35^{\circ} \mathrm{C}$. The proton concentration of the salt resolution is such once atomized at $35^{\circ} \mathrm{C}$, the collected resolution area unit aiming to be in associate degree extraordinary proton concentration vary from 6.5 to 7.2.

\subsection{Raman Effect}

It is in addition potential to look at molecular vibrations by associate inflexible scattering technique. In inflexible (Raman) scattering, associate absorbed boson is re-emitted with lower energy; the excellence in energy between the incident photons and scattered photons corresponds to the energy required to excite a molecule to a more robust undulation mode. If the polarization within the molecule doesn't couple to those different potential polarizations, then can not amendment the undulation state that the molecule started in and also the scattered gauge boson will have identical energy because the original gauge boson. This kind of scattering is thought as physicist scattering. Employs the Raman result for substances analysis. Raman spectrographic analysis is employed to research a good vary of materials, together with gases, liquids, and solids. Extremely advanced materials like biological organisms and human tissue] may also be analyzed by Raman spectrographic analysis. For solid materials, Raman scattering is employed as a tool to discover high-frequency phonon and magnon excitations. Raman measuring system is employed in region physics to live the region extinction constant and also the water vapor vertical distribution. Excited Raman transitions also are wide used for manipulating a unfree ion's energy levels, and therefore basis quit 
states. Raman analysis will be accustomed confirm the force constant and bond length for molecules that don't have an infrared spectrum. Raman amplification is employed in optical amplifiers.

\subsection{Field emission scanning electron microscopy}

Compared with convention scanning microscopy (SEM), emission SEM (FESEM) produces clearer, less electro statically distorted pictures with spatial resolution all the way down to one $1 / 2$ nanometers -3 to 6 times higher. Principle of Operation: A field-emission cathode within the electrode of a scanning microscope provides narrower inquisitor beams at low further as high negatron energy, leading to each improved spatial resolution and decreased sample charging and injury.

\section{RESULT AND DISCUSSION}

\subsection{Atomic force microscopy studies (AFM)}

Surface geographics characterization was done my Atomic Force research. The AFM scan was carried on 3 samples coated with AlN at room temperature, $200^{\circ} \mathrm{C}$ and $500^{\circ} \mathrm{C}$ for $60 \mathrm{~nm}, 60 \mathrm{~nm}$ and $80 \mathrm{~nm}$ severally. Scan was carried with semi-contact mode on sputtered AlN for a scan space of $5 \mu \mathrm{m} \times 5 \mu \mathrm{m}$ on the surface. From the AFM pictures (refer Fig.3.1 a,b,c )aluminium surface have average roughness of $6.78922 \mathrm{~nm}, 5.59142 \mathrm{~nm}$ and $16.6085 \mathrm{~nm}$ for room temperature, $200^{\circ} \mathrm{C}$ and $500^{\circ} \mathrm{C}$ temperature coatings respectively. From the results found it can be determined that due to the low average roughness, there will be low friction co-efficient decreasing the wear on the worm gear $[6,9,13]$.
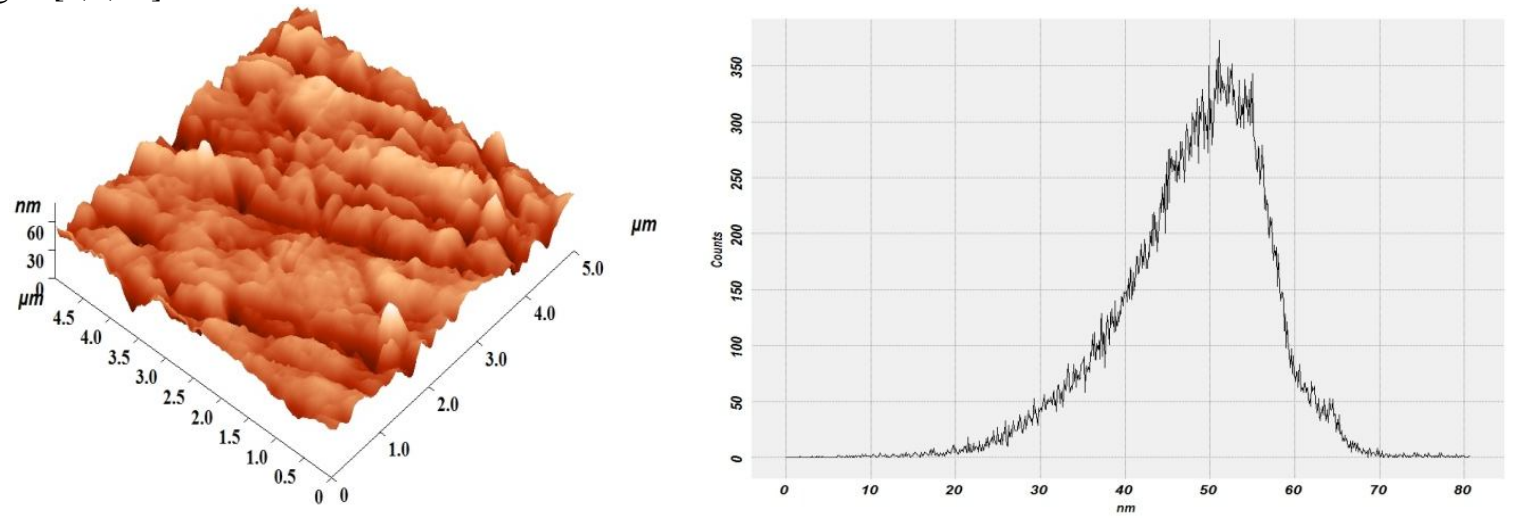

Fig 3.1(a) $5 \mu m \times 5 \mu m 3 D$ image of coated sample at room temperature
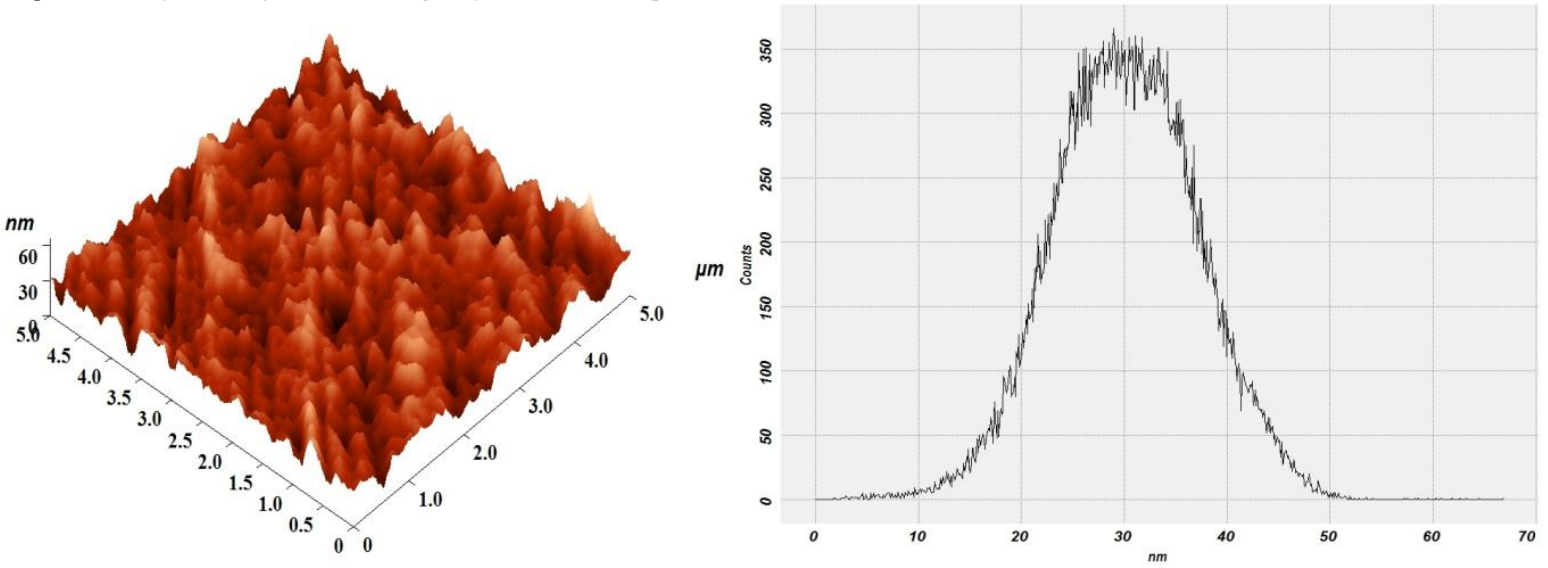

Fig 3.1(b) $5 \mu \mathrm{m} \times 5 \mu \mathrm{m} 3 \mathrm{D}$ image of coated sample at $200^{\circ} \mathrm{c}$ 

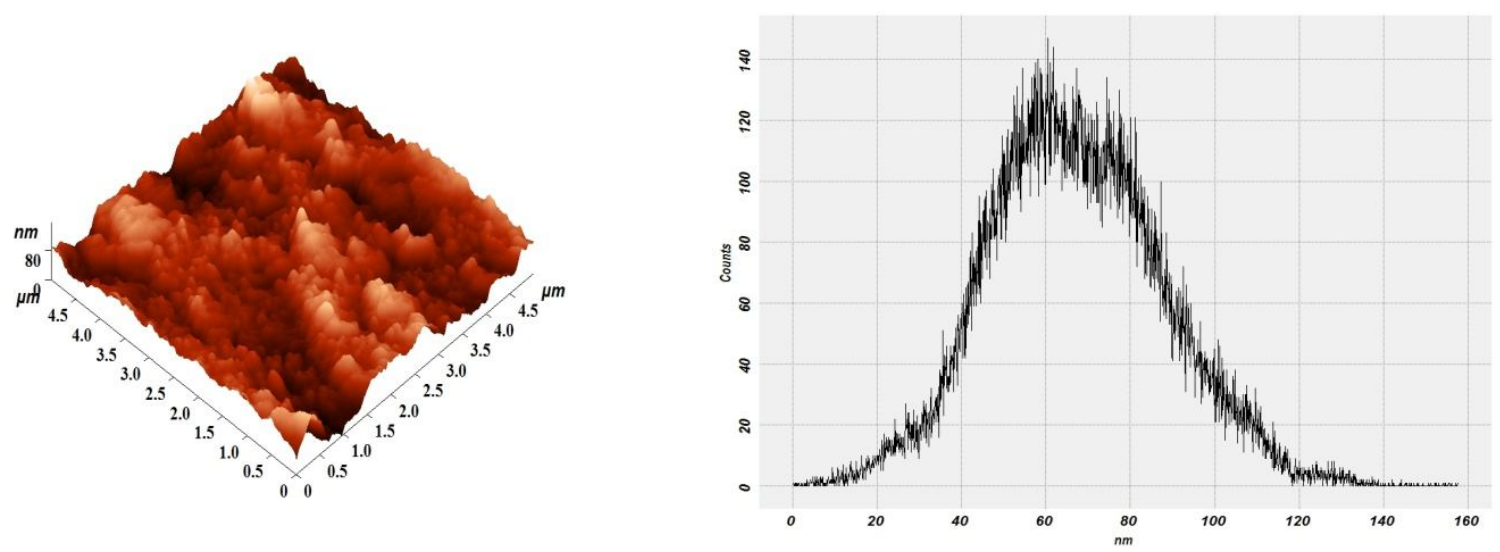

Fig 3.1(c) $5 \mu \mathrm{m} \times 5 \mu \mathrm{m} 3 \mathrm{D}$ image of coated sample at $500^{\circ} \mathrm{c}$

\subsection{X-Ray Diffraction}

The section composition then the structure of the film was studied by diffraction analysis. The XRD patterns of AlN skinny films unit of measurement shown at intervals the figure six.1.The excellent peaks (h-AlN 0002), (C-AlN 002) and (h-AlN) were obtained at intervals the power diffraction studies. The peaks of uncoated, RT, $200^{\circ} \mathrm{C}, 400^{\circ} \mathrm{C}$, $500^{\circ} \mathrm{C}, 600^{\circ} \mathrm{C}$, was compared with Origin eight and Match! Natural phenomenon patterns from the determined peaks admire the formation of hexaagonal section of AlN were indexed to stay with plane figure structure [4, 22]. Knowing the wavelength $(\lambda)$, full dimension at $[* \mathrm{fr} 1]$ most (FWHM) of the peaks ( $\beta$ ) and natural phenomenon angle ( $\square$ ), the particle size (D) was calculated victimization the scherrer formula. $D=0.9 \lambda / \beta \operatorname{Cos} \square$

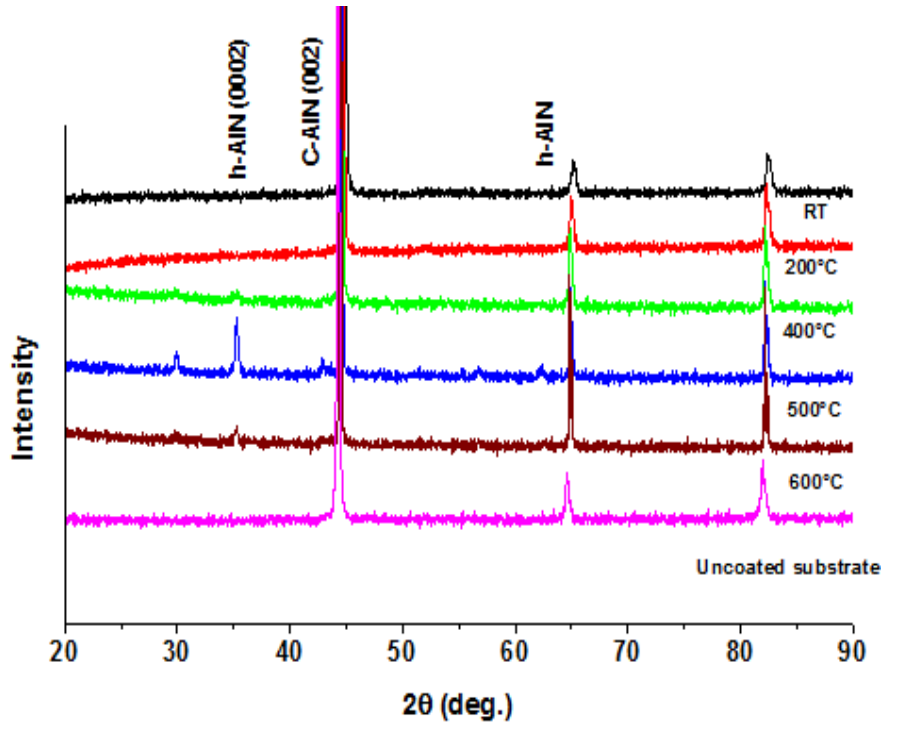

Fig.3.2 XRD pattern of the AlN thin films deposited on low carbon substrates at different temperatures.

\subsection{FESEM (Field emission scanning electron microscopy)}

Figure (3.3 a) shows FE-SEM image of Low steel (1018) .The film exhibits associate just about wonderful, twodimensional figure closely packed, cylindrical pore arrangement with an equivalent diameter and a pore interval $500 \mu \mathrm{m}, 200 \mu \mathrm{m}, 100 \mu \mathrm{m}$ severally. FE-SEM observations elucidate a spread of shapes at intervals the second nanoparticle super lattices having well-defined or multiple aspects, where many of them have plate-like or troublesome morphologies (Fig.3.3 b). Exaggerated photos (Fig.3.3 c) of the plate-like super lattice marked with one processed the two-dimensional figure compact arrangement of nanoparticles with the core size of regarding $6 \mathrm{~nm}$. 
Investigation On Micro Structural, Mechanical And Tribological Properties Of Aluminium Nitride (Aln) Coating Deposited By Rf Magnetron Sputtering
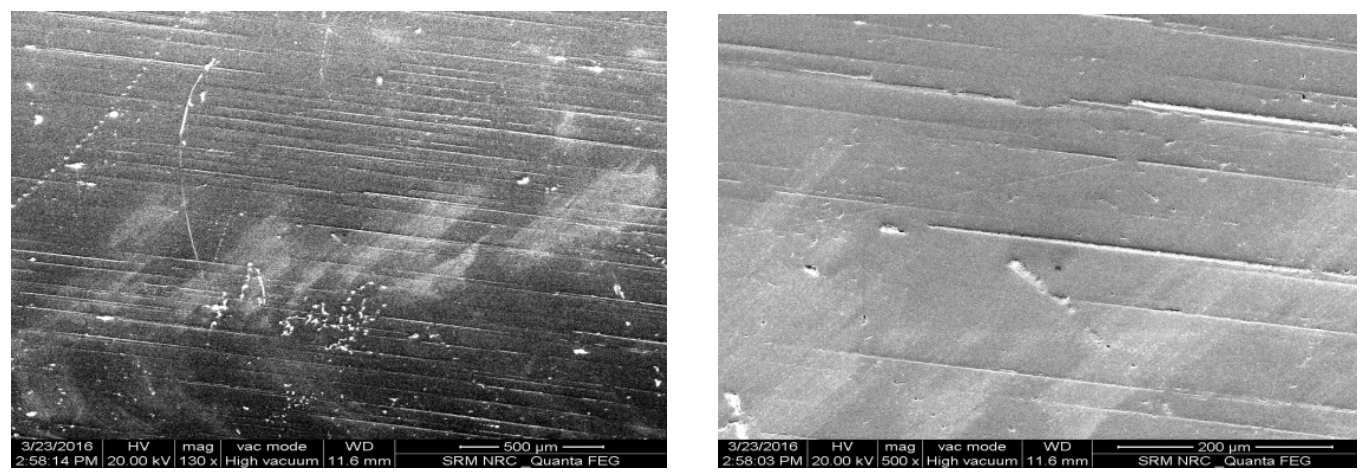

Fig. 3.3 (a) $500 \mu \mathrm{m}$

Fig.3.3 (b) $200 \mu \mathrm{m}$

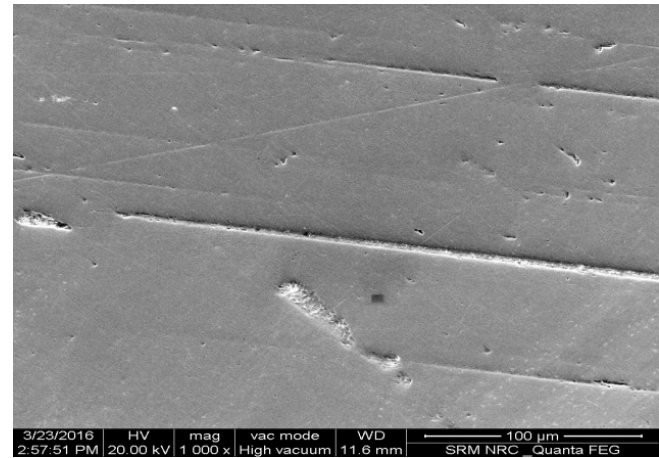

Fig. 3.3 (c) $100 \mu \mathrm{m}$

\subsection{Nanoindentation}

The hardness $\mathrm{H}$ and therefore the Young's modulus Er were measured employing a non-conductive Berkovich diamond tip at $1 \mathrm{mN}$ load at a penetration depth below 100 percent of the film thickness [9-12]. Hardness and modulus Er obtained from the nanoindentation experimental curves. The hardness and young modulus of the samples were found the values are $11.99 \mathrm{GPa}, 13.05 \mathrm{GPa}, 12.29 \mathrm{Gpa}, 23.0 \mathrm{GPa}$ and $11.12 \mathrm{GPa}$ at temperature of RT, $200^{\circ} \mathrm{C}, 400^{\circ} \mathrm{C}, 500^{\circ} \mathrm{C}$, and $600^{\circ} \mathrm{C}$, respectively. Similarly the elastic modulus values are found to be 177.06 $\mathrm{GPa}, 191.60 \mathrm{GPa}, 173.97 \mathrm{GPa}, 222 \mathrm{GPa} .170 \mathrm{GPa}$. Thus the corresponding hardness is increased the temperature of $500^{\circ} \mathrm{C}$ and relative elastic modulus of $222 \mathrm{Gpa}($ refer Fig 3.4)

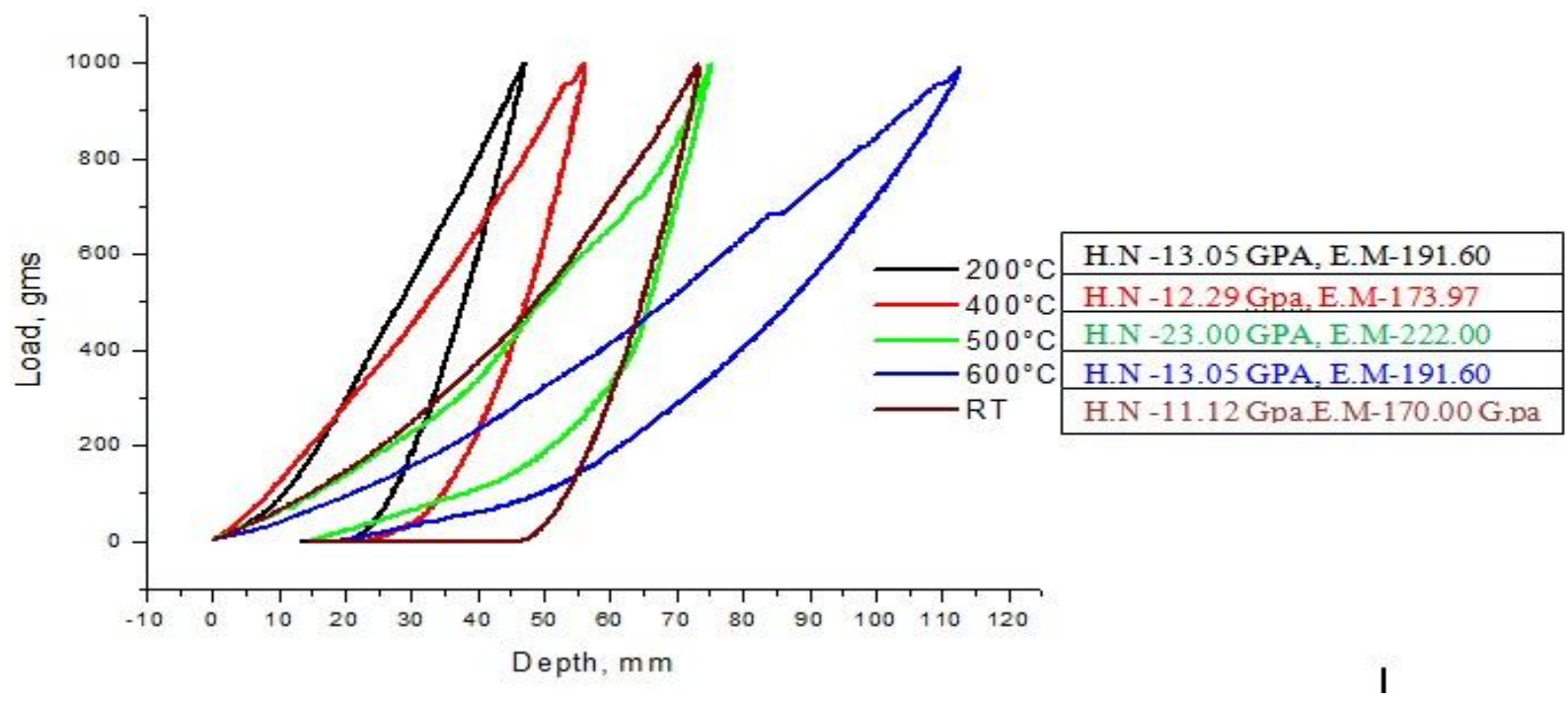

Fig.3.4 Nan indentation graph at different temperature 
The AlN samples were take a look acted for corrosion resistance properties beneath salts spray test for twelve hours. The concentration of binary compound was five. $3 \% \mathrm{NaCl}$ and therefore the temperature within the chamber was $34.5 \mathrm{C}$ to $35.5 \mathrm{C}$ the $\mathrm{pH}$ scale of the salt answer was 6.9 and gas pressure was eighteen psi. Once twelve hours of salt spray take a look at it absolutely was determined that there was no corrosion $[19,23]$. From the info no inheritable, it are often inferred that the corrosion resistance of low carbon steel (1018) has been enlarged RT, $200^{\circ} \mathrm{C}, 400^{\circ} \mathrm{C} 500^{\circ} \mathrm{C}, 600^{\circ} \mathrm{C}$.

\subsection{Wear Properties}

The coated samples would have lower corrosion and also the substrate coated at $200^{\circ} \mathrm{c}$ exhibited the simplest corrosion resistance for the coating investigated within the studies. The wear and tear resistance and also the corrosion resistance of low steel were hyperbolic by AlN coatings.

\section{CONCLUSION}

Aluminium Nitride (AlN) thin films were prepared on low carbon steel substrates at different temperatures using RF magnetron sputtering method. The prepared films were characterized by XRD, AFM and Nano indentation techniques to study the microstructural and mechanical properties of the films respectively. The XRD analysis showed that the film prepared at RT and $200{ }^{\circ} \mathrm{C}$ showed the amorphous nature of the films. The films prepared at $400-600^{\circ} \mathrm{c}$ showed the peaks corresponding to hexagonal (0002) and cubic (002) structure, preferential orientation along (002) for the sputtered AlN films with cubic structure and also hexagonal phases are present at low substrate temperature[24].

AlN coatings were with successfully prepared RF magnetron sputtering on low steel substrate. AlN coatings would possibly accomplish higher corrosion polarization resistance and relatively stable corrosion potential at intervals the SBF surroundings than the uncoated low steel. Therefore, the coated samples would have a lower corrosion and therefore the substrate coated at $200^{\circ} \mathrm{C}, 500^{\circ} \mathrm{C}$ exhibited the most effective corrosion resistance for the coating investigated within the studies. The damage resistance and therefore the corrosion resistance of low steel was multiplied by AlN coating[8-12]. Aluminium Nitride (AlN) provides good protection for corrosion for the metal substrates. The roughness of the films are $6.78922 \mathrm{~nm}, 5.59142 \mathrm{~nm}$ and $16.6085 \mathrm{~nm}$ at temperatures of respectively. In the AlN thin films, the surface topography [10-14] is composed of clusters of same sizes with irregular shapes. The irregular form of grains counsel that at low substrate temperatures the mechanical energy isn't comfortable for the conjugation of the grains which can diode to the presence of extra phases as evident from the XRD analysis. it's evident from the AFM micrographs that the form of the grains changes with increasing substrate temperature additionally to the grain size[3-5].

\section{REFERENCES}

[1] Aurelian C. Galca, George E. Stan, Liliana M. Trinca, C. Catalin Negrila, Leona C. Nistor, Thin Solid Films 524 (2012) 328-333

[2] V.N. Inkin, , G.G. Kirpilenko, A.J. Kolpakov, Diamond and Related Materials 10 (2001) 1314-1316

[3] Bin Liu, , B.Y. Jiang, Y.Fu, D.J. Cheng, X.F. Wu, S.Z. Yang Thin Solid Films 349 (1999) 111-114

[4] Arshad Mahmood, , Nikifor Rakov, Mufei Xiao, Materials Letters 57 (2003) 1925 - 1933

[5] Motohiro Yamada, , Toshiaki Yasui, Masahiro Fukumoto, Koyata Takahashi, Thin Solid Films 515 (2007) 4166-4171

[6] Boyan Li, , Jianjun Li ,LiWu, Wei Liu, Yun Sun, Yi Zhang, Journal of Alloys and Compounds 627 (2015) 1-6

[7] C. Ristoscu,Thin, C. Ghica, E.L. Papadopoulou, G. Socol, D. Gray, B. Mironov,.N. Mihailescu, C., Solid Films 519 (2011) $6381-6387$

[8] Hai-Wei Xin, , Lin-Hai Tian, Jun-De Pan, QiHe, Zhong Xu , Zhi-Ming Zhang, Surface and Coatings Technology 131 2000 167-170

[9] Motohiro Yamada, , Toshiaki Yasui, Masahiro Fukumoto, Koyata Takahashi, Thin Solid Films 515 (2007) 4166-4171

[10] Xubo Yan, Yuliang Dong, Haiqing Li, Jun Gong, Chao Sun, , Materials Letters 64 (2010) 1261-1263

[11] Aurelian C. Galca, Thin, George E. Stan, Liliana M. Trinca, C. Catalin Negrila, Leona C. Nistor, Solid Films 524 (2012) 328-333

[12] G.Ecke, , G. Eichhorn, J.Pezoldt, C.Reinhold , T.Stauden,F.Supplieth, G. Eichhorn, J.Pezoldt , C.Reinhold , T.Stauden,F.Supplieth, Surface and CoatingsTechnology98(1998)1503-1509

[13] A. Kale, , R.S. Brusa, A. Miotello, Applied Surface Science 258 (2012) 3450- 3454

[14] C. T. M. Ribeiro, F. Alvarez, A. R. Zanatta, Apl. Phys. Lett 81, 1005 (2002).

[15] J. C. Loretz, B. Despax, P. Marti, A. Mazel, Thin Solid Films 15, 265 (1995).

[16] X. S. Miao, Y. C. Chan, Z. Y. Lee, J. Electronic Materials 26(1), 21-24 (1997).

[17] T. P. Drusedau, Th. Neubert, A. N. Panckow, Surface and Coatings Technology 163-164, 164-168 (2003).

[18] C. Henlein, J. K. Grepstad, S. Einfeldt, D. Hommel, T. Berge, A. P. Grande, J. Appl. Phys. 83,2990 (1998).

[19] H. Liddell, Computer-Aided Techniques for Design of Multilayer Filters, Bristol, Adam Hilger,p.19(1981).

[20] Tz. Babeva, S. Kitova, I. Konstantinov, Appl. Opt. 40, 2682-2686 (2001).

[21] V. Panayotov, I. Konstantinov, Proc. SPIE 2253, 1070-1079 (1994).

[22] I. Konstantinov, Tz. Babeva, S. Kitova, Appl. Opt. 37, 4260-4267 (1998).

[23] V. Panayotov, I. Konstantinov, Appl. Opt. 30, 2795-2800 (1991).

[24] Tz. Babeva, S. Kitova, B. Mednikarov, I. Konstantinov, Appl. Opt. 41, 3840-3846 (2002). 